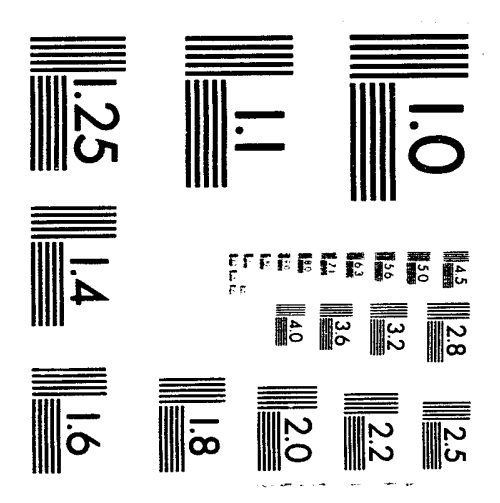



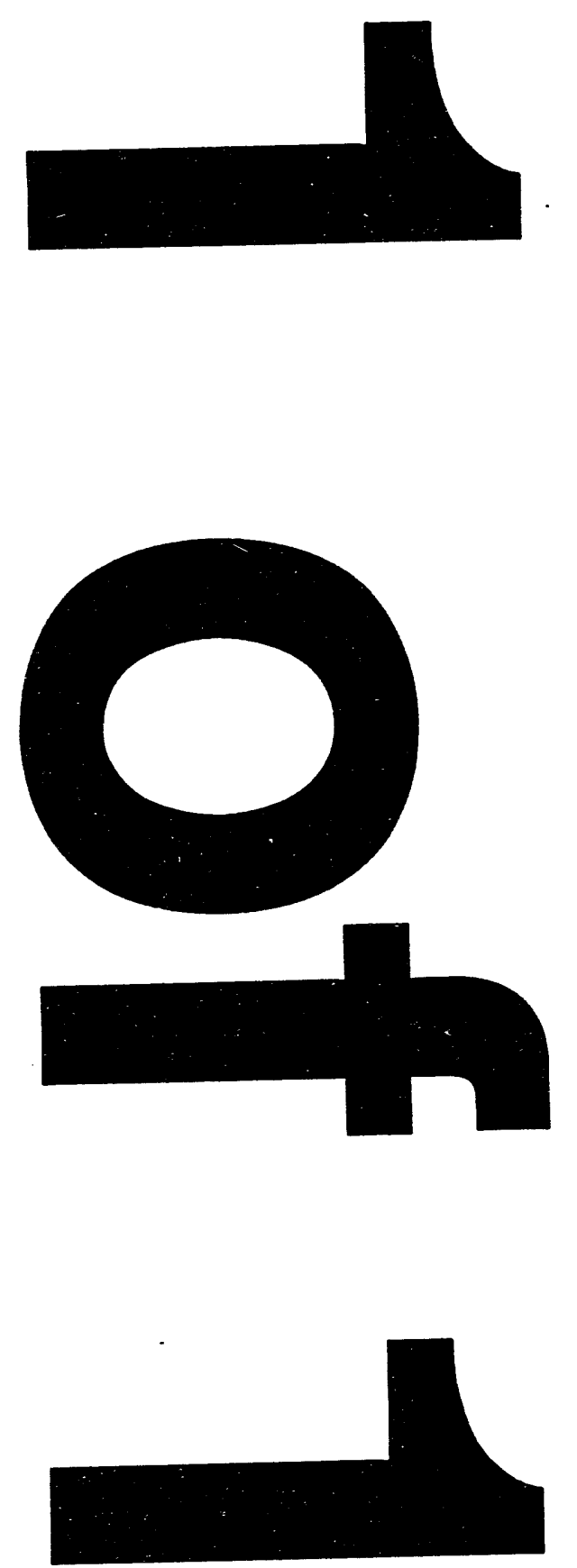
Distribution

Category UC-814

SAND92-2333

Unlimited Release

Printed April 1994

\title{
The Effect of Sliding Velocity on the
}

\section{Mechanical Response of an Artificial Joint in}

\author{
Topopah Spring Member Tuff \\ William A. Olsson \\ Geomechanics Department \\ Sandia National Laboratories
}

\begin{abstract}
A smooth artificial joint in Topopah Spring Member tuff was sheared at constant normal stress at velocities from 0 to $100 \mu \mathrm{m} / \mathrm{s}$ to determine the velocity-dependence of shear strength. Two different initial conditions were used: (1) unprimed-the joint had been shear stress free since last application of normal stress, and before renewed shear loading; and (2) primed-the joint had undergone a slip history after application of normal stress, but before the current shear loading. Observed steady-state rate effects were found to be about 3 times larger than for some other silicate rocks. These different initial conditions affected the character of the stress-slip curve immediately after the onset of slip. Priming the joint causes a peak in the stress-slip response followed by a transient decay to the steady-state stress, i.e., slip weakening. Slide-hold-slide tests exhibit time-dependent strengthening. When the joint was subjected to constant shear stress, no slip was observed; that is, joint creep did not occur. One set of rate data was collected from a surface submerged in tap water; the friction was higher for this surface, but the rate sensitivity was the same as that for surfaces tested in the air-dry condition.
\end{abstract}


This report was prapared under the Yucca Mountain Project WBS number 1.2.3.2.7.1.4. The data in this report was developed subject to QA controls in QAGR S1232714; the data is not qualified and is not to be used for licensing. 


\section{Contents}

1 Introduction 1

1.1 Review of the Constitutive Equations . . . . . . . . . . . . . 2

2 Experimental Technique and Sample Preparation 5

3 Results and Discussion $\quad 6$

3.1 The effect of Velocity Changes at Constant Normal Stress . . . . . . . . . . . . . 6

3.1 .1 Unprimed surfaces $\ldots \ldots \ldots \ldots$

3.1.2 Primed surfaces $\ldots \ldots \ldots \ldots \ldots$

4 Creep $\quad 11$

4.1 Unprimed Surface $\ldots \ldots \ldots \ldots \ldots$

4.2 Primed Surface . . . . . . . . . . . . . . . . . . . . 12

5 Conclusions $\quad 13$

6 References 15 


\section{List of Figures}

1 Definition sketch for constitutive parameters $a, b$, and $L$. The imposed load-point velocity is such that $V_{*}<V \ldots \ldots \ldots \ldots$

2 Spring and block analogue to sliding of laboratory-sized joint. $V_{0}$ is the load-point velocity imposed by the loadframe, $\tau$ is the resisting shear traction, and $V$ is the velocity of the block. . . . . . . . . . . . . . . . . . 4

3 Sample configuration for rotary shear experiments on joints. . . . . . . . 6

4 A stress-slip curve showing the different response for the same interface in the primed and unprimed states. Loops labelled $A$ through $D$ have been isolated to illustrate the concept of priming. . . . . . . . . . . . . . . . . 8

5 The stress-slip curves at different sliding velocities for unprimed surfaces. All experiments started at the same initial placement and at $5 \mathrm{MPa}$ normal stress. . . .

6 The effect of sliding velocities (indicated in $\mu \mathrm{m} / \mathrm{sec}$ ) on a primed surface. Note the differences between the way slip develops in these experiments with those of an unprimed surface shown in Figure 1. . . . . . . . . . . . . . 10

7 Rate sensitivities of the steady-state friction coefficient for various initial conditions. 10

8 Variation of friction in a slide-hold-slide test. Note the stress-relaxation at each displacement hold, and the transient strengthening. . . . . . . . . . . . . 12

9 The effect of displacement holds of various lengths on the strength. . . . . . . . 13

10 A creep test near the slip stress on a primed surface. . . . . . . . . . . . . . . . . 14 


\section{Introduction}

The Topopah Spring Member of the Paintbrush Tuff within Yucca Mountain, Nevada, has been selected as a potential repository of high-level nuclear wastes. The Yucca Mountain Site Characterization Project (YMP) of the Office of Civilian Radioactive Waste Managememnt (OCRWM) Program has been assigned the task of determining the suitability of the Yucca Mountain site. Among the concerns being investigated, the characterization of the mechanical properties of the host rock has direct relevance to repository design, and to pre- and post-closure performance assessment.

Licensing of a nuclear-waste repository by the Nuclear Regulatory Commission (NRC) requires, among other things, demonstration of the long-term usability of the underground portion of the repository. Such a demonstration involves analysis of the mechanical response of the rock mass to the presence of underground openings and heat-producing waste over long periods of time. This report presents data on the time-dependent properties of a fracture as measured in rate-stepping and creep experiments in support of design and preformance stability issues. The test material was taken from a block of welded, devitrified Topopah Spring tuff (Price et al., 1987).

Mechanical discontinuities such as faults, bedding planes, or joints are important mechanical constituents of most rock masses; they increase the compliance and decrease the strength of the rock mass. Stress changes and slip-induced dilation can affect the contributions of mechanical discontinuities to fluid permeability of the rock mass (Olsson, 1992; Olsson and Brown, 1993). Furthermore, the constitutive response of joints in silicate rocks is of a type that can lead to dynamic instabilities under a range of conditions. These instabilities are referred to as "stickslip" and manifest themselves in experiments as jerky sliding accompanied by stress drops. This behavior on a larger scale is thought to be analogous to earthquakes (Brace and Byerlee, 1966). It has been shown (Wong, 1992) that most mine seismicity, e.g., rock bursts and bumps, is due to slip on geologic discontinuities. Further, it has been established that slip on joints in Grouse Canyon welded tuff is accompanied by acoustic emissions (Holcomb and Teufel, 1982) and therefore it is important to explain this aspect of time-dependent joint behavior of tuff.

For simplicity, the term "joint" is used throughout this report, but the results apply to any interface in rock with vanishingly small tensile strength.

The shear resistance of a joint depends on the normal stress history across it, the sliding velocity history, the temperature, the roughness, and the presence of water and gouge. It is generally accepted that normal stress is the dominant factor controlling the shear strength of a given joint and that all other effects have second order influence. This report focuses on time- or rate-dependence. It is important to understand that these effects, though lesser in magnitude of associated stress changes, can have important consequences. For example, it has been established that the details of the rate-dependence part of the constitutive description can either enhance or suppress instabilities in slip (Gu, et al., 1984; Rice and Ruina, 1983; Ruina, 1983). As such, these rate effects have a direct 


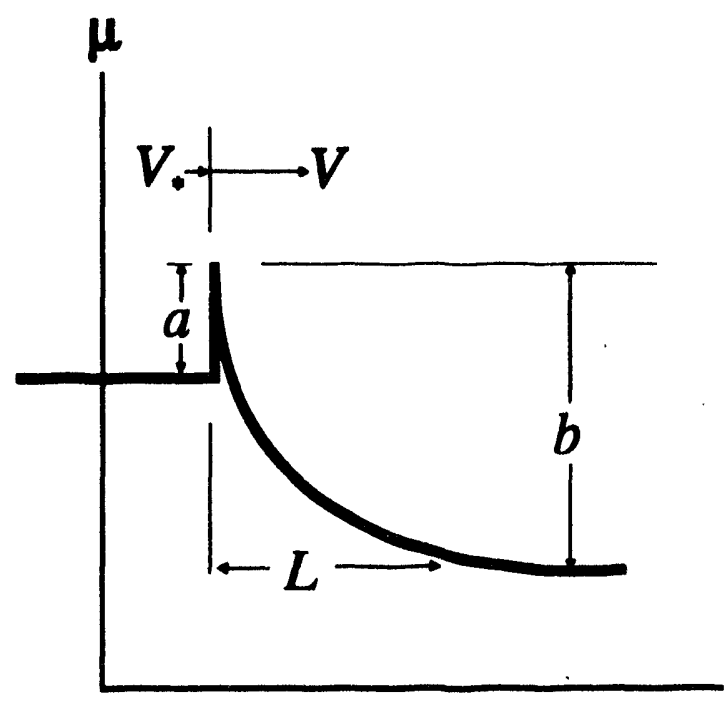

\section{SLIP}

Figure 1: Definition sketch for constitutive parameters $a, b$, and $L$. The imposed load-point velocity is such that $V_{*}<V$.

bearing on mine seismicity.

Constitutive equation development for the time-dependent slip of interfaces at invariable normal stress is limited at this time to encompassing the effects of velocity, the history of velocity and the state of the surface. The theory is purely phenomenological in that no underlying physical process has been identified that predicts the response.

\subsection{Review of the Constitutive Equations}

The resistance to slip $\tau$ is coupled to the normal stress $\sigma$ to dominant order through the coefficient of friction $\mu$ according to the slip condition

$$
\tau-\mu \sigma \leq 0 .
$$

When the net shear stress $\tau-\mu \sigma$ is less than zero there is no slip. When absolute equality holds, the rate effects enter the problem. Whether creep will occur for $\tau-\mu \sigma<0$ is not yet well-documented. This report presents results of several short-term creep tests, and this issue is now being investigated in long-term (about 3 months) creep tests. When the net shear stress on a joint is less than zero, the rock mass response in shear is approximately the same as that of the intact rock.

There are two classes of frictional constitutive laws: slip-dependence (often referred to as slipweakening) and rate- and state-dependence. Slip-dependence laws embody monotonic surface 
evolution that may be related to damage accumulation. These laws have the defect that there is no explicit rate-dependence and observed repeated instabilities are not predicted. The rate- and state-dependence law can predict repeated behavior, but may not be appropriate for the initial stages of slip wheri strong surface evolution to a steady-state takes place. Fracture behavior spans both types of description. In general terms, frictional slip has elements of both discrete memory (slipdependence) and fading memory (rate- and state-dependence) of past stress and velocity (Olsson, 1987b).

The rate effects described herein are best discussed within the context of the rate- and statedependence model. Experimental work of Dieterich $(1972,1978,1979)$ followed by Ruina (1980, 1983) and Dieterich (1981) led to the development of the currently accepted formulation for effects of sliding velocity history and time on joint hehavior (Ruina, 1983; Rice and Ruina, 1983). Rice and his coworkers (Gu et al., 1984; Rice and $\mathrm{Gu}, 1983$ ) implemented the constitutive equations into predictive stability analyses. Tullis and Weeks (1986) gave an account of results from rotary shear experiments on granite within the framework of this theory.

The constitutive model is based on observed changes in friction during and immediately following abrupt changes in velocity. The state of the surface is included through time-evolving state variables. The basic equations describing this rate- and state-dependent behavior at constant normal stress and when the slip condition is satisfied (1) are:

$$
\begin{gathered}
\mu=\mu_{*}+b_{i} \Psi_{i}+a \ln \left(V / V_{*}\right), \\
d \Psi_{i} / d t=-\left(V / L_{i}\right)\left[\Psi_{i}+\ln \left(V / V_{*}\right)\right] .
\end{gathered}
$$

In these equations, $V$ is the sliding velocity, $\Psi_{i}$ are state variables that evolve with time, $\mu_{*}$ is the friction at an arbitrary reference velocity $V_{*}$. The parameters $a$ and $b_{i}$ are constants to be determined, and the $L_{i}$ are the distances over which the $\Psi_{i}$ evolve. A simple experiment, such as shown in Figure 1, provides all the parameters.

Differentiation of the constitutive equations, simplified to one state variable $(i=1)$, leads to the following definitions of the variables $a, b$, and $L$ (Fig. 1):

$$
\begin{aligned}
\left.\frac{\partial \mu}{\partial \ln V}\right|_{\Psi} & =a \\
\frac{d \mu^{\Delta s}}{d \ln V} & =a-b \\
\left.\frac{\partial \mu}{\partial x}\right|_{V} & =-\frac{\mu-\mu^{\rho s}}{L} .
\end{aligned}
$$

Thus, $a$ is the instantaneous response following a jump in the velocity, and $a-b$ measures the difference between the current and former steady-state values of friction. The steady-state friction, 

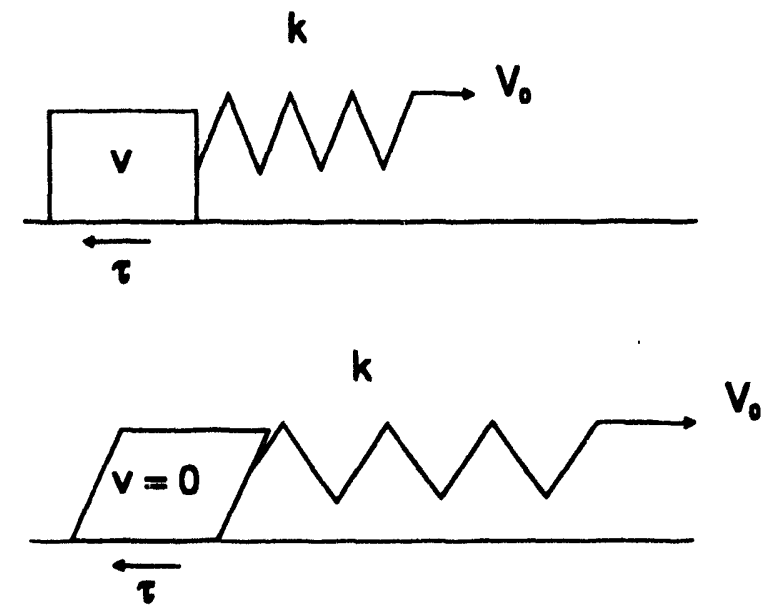

Figure 2: Spring and block analogue to sliding of laboratory-sized joint. $V_{0}$ is the load-point velocity imposed by the loadframe, $\tau$ is the resisting shear traction, and $V$ is the velocity of the block.

$\Psi=0$, is

$$
\mu^{s s}=\mu_{*}+(a-b) \ln \left(V / V_{*}\right) .
$$

If $\mu^{s s}<\mu_{*}$, then the response is said to be velocity weakening and $a-b<0$. If $\mu^{\text {se }}>\mu_{*}$, then the response is said to be velocity strengthening and $a-b>0$. The type of response observed for silicate rocks depends on the normal stress-low normal stress promotes stick-slip behavior, and high normal stress promotes velocity strengthening. Blanpied et al. (1987) have found that for $V_{0}$ greater than about $100 \mu \mathrm{m} / \mathrm{s}, a-b$ becomes positive, implying stability. Elevated temperatures also can promote stable response (Blanpied et al., 1991). It is not clear whether the state changes, $d \Psi \neq 0$, when the surfaces are in stationary contact to begin with, that is, when the previous steady state is actually the zero velocity history $(V=0$, for all previous time). The evolution of $\Psi$ is clear when the first and second steady-states are at finite velocities, but if $V_{*}=0$ for a long time, does the state change?

Joints are interfaces embedded in a deformable medium and as such do not necessarily slide over their whole extent simultaneously. Therefore, inhomogeneous slip may be important in the field and in the laboratory (Olsson, 1984). Rice (1983) has shown that the inhomogeneous slip regime associated with the advancing slip zone boundary is of the order of 1 metre. For the rotary shear configuration in particular, it has been shown that slippage is essentially uniform (Olsson, 1987b). Evidently, for normal laboratory sample dimensions, it is permissible to interpret laboratory friction data in terms of a rigid block being slid over a smooth surface by a force pulling on a spring connected to the block (Fig. 2).

The force, displacement, and velocity $V_{0}$ at the distal end of the spring are called the load-point values. In the load frame used in this investigation, the torque and angular displacement are applied at one end of the loading column while the joint is at the other. Thus, constant displacement rates 
are applied through the elastic loading column, and because of the finite stiffness of the column there may be a difference in the velocity of sliding and the applied velocity, $V_{0}-V$. This compliant load application is similar to a joint being loaded by the surrounding compliant rock and, in this sense, the laboratory experiment simulates nature. The difference in load-point velocity compared to joint-wall relative velocity emphasizes the importance of separating constitutive response of the joint from the loading-system response.

The spring-block system is described by

$$
\frac{d \tau}{d t}=k\left(V_{0}-V\right)
$$

where $k$ is the spring constant, $V_{0}$ is the velocity at the load point, and $V$ is the velocity of the block. If the system unloading stiffness $k$ is such that

$$
k \leq \frac{b-a}{L},
$$

then the system will be prone to instablility in the form of jerky slipping and sudden stress drops (Dieterich, 1978). This shows how the value of the constitutive parameters $b$ and $a$ when combined with the properties of the loading system are important to stability. Natural joints will have different properties depending on geometric factors, mainly the roughness and degree of interlocking of adjacent joint walls. A different problem not considered here is the effect of gouge on the behavior of joints. Because the response of a joint depends on some convolution of the basic smooth-surface friction with its topographic properties, it is most illuminating to measure the magnitude of the effects of the variables on the smooth rock surfaces first, and then introduce the very complicated problem of surface roughness. The focus here is on the effects of sliding velocity, the history of the velocity, and the initial state of the sliding surface on strength of smooth surfaces.

\section{Experimental Technique and Sample Preparation}

The results reported here were obtained in rotary shear experiments (Christensen et al., 1974; Kutter, 1974; Olsson, 1987ab, 1988ab, 1990, 1992; Xu and Frietas, 1988; Tullis and Weeks, 1986; Weeks and Tullis, 1985; Yoshioka and Scholz, 1989). In this type of experiment, the sample is composed of two, short, hollow tubes of rock that are pressed together under controlled load, and then torque is applied to cause sliding on the interface (Fig. 3). Further details may be obtained from (Olsson, 1987a).

The sample used in this study was sawed, then ground flat and perpendicular to the cylinder axis. Outside and inside diameters were $88.9 \mathrm{~mm}$ and $50.8 \mathrm{~mm}$, respectively. The short (approx. $50 \mathrm{~mm}$ ) cylinders were cemented to metal disks with epoxy, and then reground to ensure that the joint was parallel to the surfaces of the metal disks. The joint surfaces were then sandblasted to 


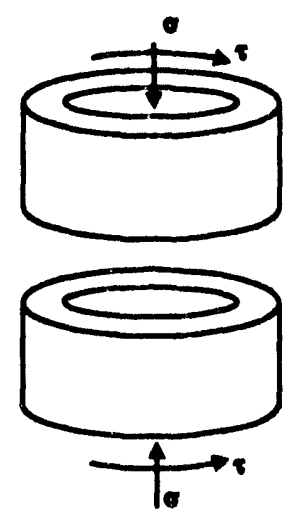

Figure 3: Sample configuration for rotary shear experiments on joints.

a dull finish. Before the experiments, the joint was slid back and forth under low normal stress of around $1 \mathrm{MPa}$ to "run-in" the surface. This procedure stabilizes the stress-slip response loops and makes them reproducible under nominally identical test conditions. The experiments were performed on clean surfaces that had been run-in. In this report, the terms "mean slip" and "slip" are used interchangeably for angle of rotation in radians times $\left(D_{o}+D_{i}\right) / 4$, where $D_{o}$ and $D_{i}$ are the outer and inner diameters, respectively. The load-point slip was corrected to slip by subtracting $\tau /$ (unloading slope) from the measured displacements. This difference in the stress-slip reponse when using these two measures can be seen by comparing the initial loading portion of the curves in Figures 4 and 5.

\section{Results and Discussion}

\subsection{The effect of Velocity Changes at Constant Normal Stress}

It had been found in earlier studies on tuff (Olsson, 1987a, 1988b) that there exist two recognizable initial conditions for smooth, topographically uncorrelated surfaces under the same test conditions: unprimed and primed. To create the unprimed initial condition, the initially separated joint walls are brought together and normal stress is applied; then the shear test is performed. In the primed condition, the joint has undergone some slip at non-zero normal stress, but now the contact is stationary; the shear test is performed on this joint. The response for these two states to increasing shear stress (Fig. 4) is significantly different. For the unprimed joint, the shear stress rises steadily to the initial slip stress (analogous to the initial yield stress in solids), then rolls over to the steadysliding value, which remains essentially constant thenceforth. On the other hand, for the primed surface, the shear stress rises steadily to the initial slip stress, then breaks over discontinuously to the steady sliding value. Often, a peak in stress is observed, followed by a rapid decline to the steady sliding value. The difference in response has been postulated to be due to inhomogenous, 

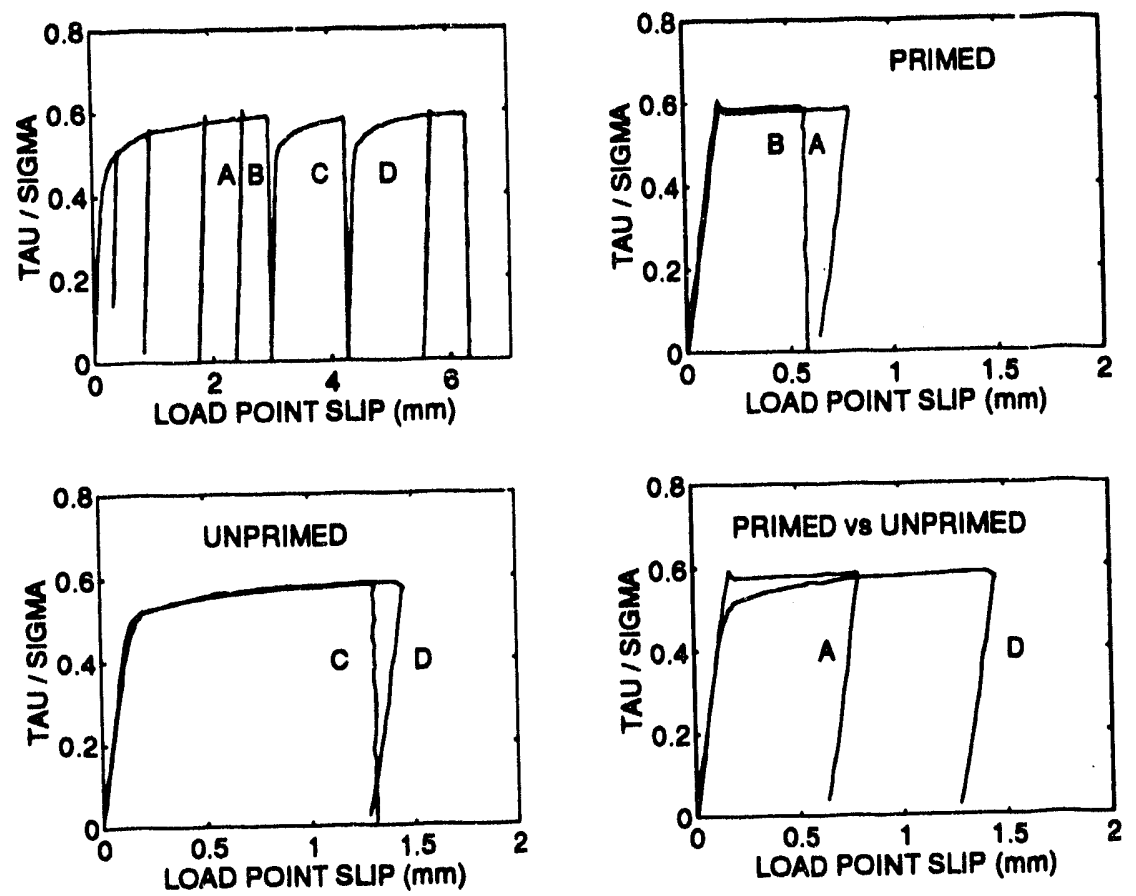

Figure 4: A stress-slip curve showing the different response for the same interface in the primed and unprimed states. Loops labelled $A$ through $D$ have been isolated to illustrate the concept of priming.

locked-in stress on the interface (Olsson, 1987b). In the Introduction, it was pointed out that peaks in the stress-slip curve due to velocity weakening can lead to instabilities in slip. The type of peak shown in Figure 4 is slip weakening and thus can also lead to instabilities.

The importance of primed versus unprimed joints lies in their different responses. By way of illustration, compare the sliding behavior of an in situ joint that has undergone some amount of shear during its history to that of the same joint cut out from its surroundings for either in situ or laboratory testing. The shear stiffness (defined as the slope of the stress-slip curve after the onset of slip) and strength of the tested joint will be less than its undisturbed counterpart, and the onset of slip will be more gradual and less prone to sudden slippage. Further, stability related response that may characterize the in situ, primed, joint will not be evident in data from the test specimem.

In geophysical applications, the concern centers around continual episodes of sliding separated by periods of stationary contact. Because the normal stress, in the experimental program, was approximately constant, the constitutive equations (2)-(10) seem to capture most of the important phenomena. Although zero velocity is a particular history of velocity, it is not clear whether these equations apply to loading of unprimed surfaces. It is important to explore this point because joints, 


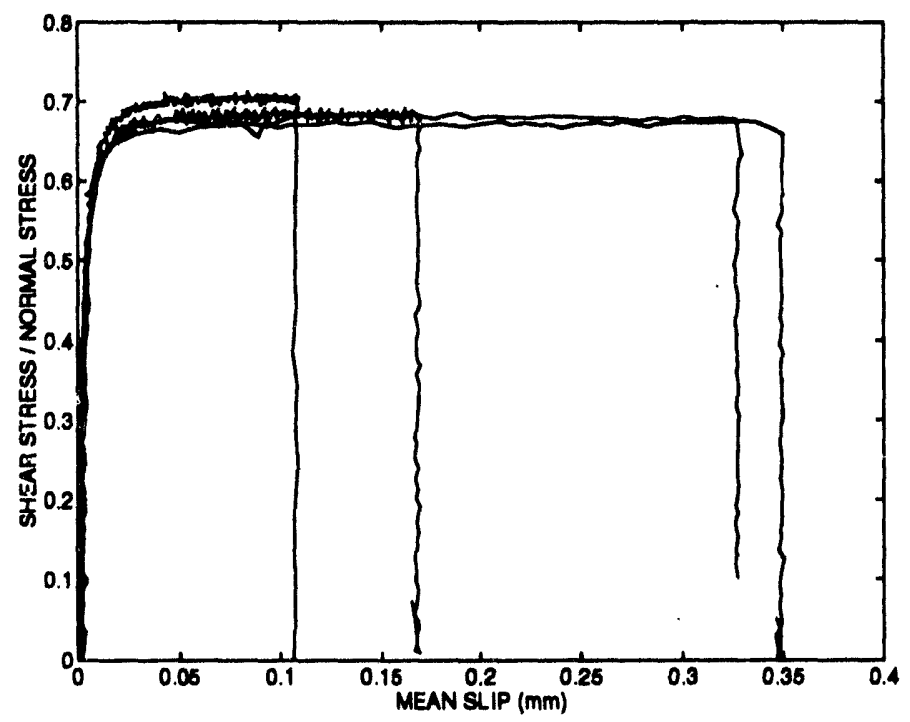

Figure 5: The stress-slip curves at different sliding velocities for unprimed surfaces. All experiments started at the same initial placement and at $5 \mathrm{MPa}$ normal stress.

unlike faults, have not undergone large displacements.

\subsubsection{Unprimed surfaces}

To measure the effects of sliding velocity on the response of unprimed surfaces, the joint was slid at a constant velocity to a preselected total slip, then the shear stress and the normal stress were reduced to zero, and then the joint returned to zero slip. Next the normal stress was reapplied, and the joint reloaded in shear and subsequently unloaded as before. This was repeated at each desired velocity, always starting from the same relative position. Between each experiment, the sample was cleaned of gouge with a blast of compressed air. In this way the effect of sliding at four different velocities for an unprimed surface was measured. The velocities were varied by decades from $0.1 \mu \mathrm{m} / \mathrm{s}$ to $100 \mu \mathrm{m} / \mathrm{s}$. The results are shown in Figure 5 .

The curves from experiments at lower velocities have a "fuzzy" aspect caused by digital noise, and this is insignificant. Irrespective of velocity, each curve has the same shape. They all become nonlinear in the neighborhood of $\mu=0.5$ and then roll over to the steady friction within $0.05 \mathrm{~mm}$ of slip. The steady friction is function of the velocity-the higher the velocity, the lower the friction. These data are summarized below as "constant rate, unprimed" in Figure 7.

Because the joint remains in stationary contact while being loaded to slip at different velocities, the initial (vertical) parts of the curves also represent displacement hold tests with differing hold 


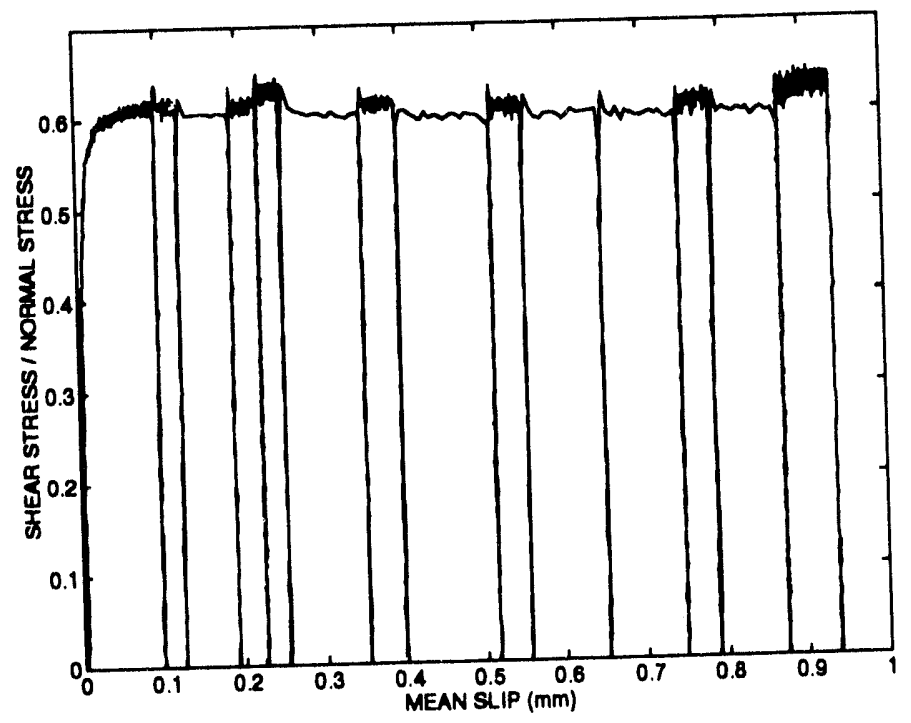

Figure 6: The effect of sliding velocities (indicated in $\mu \mathrm{m} / \mathrm{sec}$ ) on a primed surface. Note the differences between the way slip develops in these experiments with those of an unprimed surface shown in Figure 1.

times on unprimed joints. It has been observed that friction increases during nominally stationary contact of granite (Dieterich, 1972) and welded tuff (Teufel, 1981). Those tests were done in the primed condition and, therfore, it is interesting to examine the possibility of time-dependent strengthening for the unprimed surfaces as tested here. The hold times corresponding to load-point velocities of $0.1,1,10$, and $100 \mu \mathrm{m} / \mathrm{s}$ were, respectively, 7.75, 31.3, 172, 1203 seconds. These hold times spanned the same range as those applied to a primed surface, as discussed in sections 3.2 and 4.2. The lack of any apparent effect of different hold times, especially the appearance of a peak, is to be contrasted with the results presented below for slide-hold-slide experiments on a primed joint.

\subsubsection{Primed surfaces}

Figure 6 illustrates the effects of different sliding velocities on a primed joint. At the beginning (when the surface is unprimed) the stress increases and rolls over smoothly. At $0.1 \mathrm{~mm}$ of slip, the shear stress was reduced to zero and again increased at the same rate $(1 \mu \mathrm{m} / \mathrm{s})$. This time, the stress rises to a peak and then rapidly descends to the steady value. Each successive cycle on the now primed surface shows a similar peak and distinct, lower, sliding stress that depends on the applied velocity. Each vertical segment represents unloading at the load-point velocity of $1 \mu \mathrm{m} / \mathrm{s}$, and loading at the new load-point velocity. Note that each loading phase is a hold-time test for 


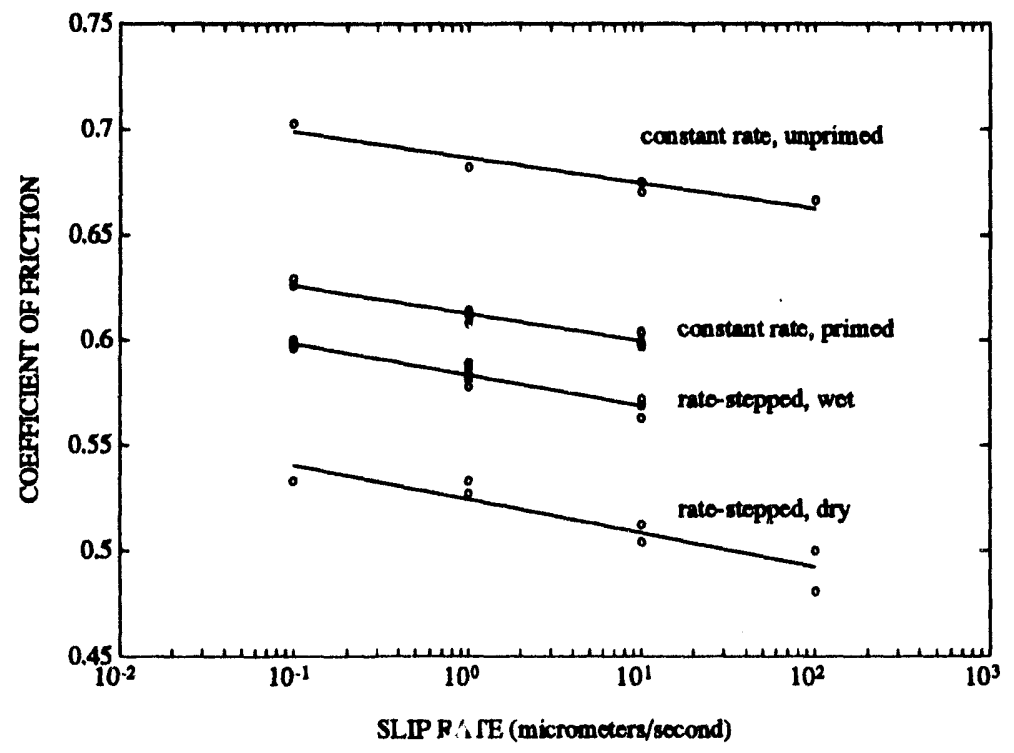

Figure 7: Rate sensitivities of the steady-state friction coefficient for various initial conditions.

each of the different velocities for a primed surface. The response now is typical for loading of primed surfaces-there exists a peak in the stress-slip curve, which decays rapidly with slip to a steady-state value. The steady portion is rate dependent and these data are included in Figure 7 as "constant rate, primed".

Data from previous rate-stepping (as sketched in Figure 1) experiments (Olsson, 1987a, 1988a) on dry surfaces, and new data from a surface submerged in room-temperature tap water are also plotted in Figure 7. The rate-stepping experiments are by their very nature carried out on primed surfaces. The greater friction for the wet surface compared to the dry surface was also found in an earlier study on a different tuff (Teufel, 1982). It appears that the steady-state friction of an unprimed surface is greater than that for a primed surface. An important aspect of Figure 7 is the parallelism of the various lines. These data give $a-b \approx 0.014$ for smooth, bare surfaces of Topopah Spring Member tuff; this is about 3 times that value observed for granites.

Another aspect of time-dependent joint slip is shown in Figure 8. Here the remote velocity $V_{0}$ is held at zero for different lengths of time after some sliding (Fig. 9). Between each test $V_{0}=5 \mu \mathrm{m} / \mathrm{s}$. The strengthening during displacement holds was suggested (Dieterich, 1972) to be related to growth of asperity area during stationary contact. Ruina (1983), however, asserts that the strengthening is a result of small amounts of slip that take place while the load point is stationary, rather than the time during which the joint walls are in stationary contact. With regard to equation (3), for $V_{0}=0$, no evolution of state (strengthening) is predicted to occur. Dieterich (1981) used a different formulation for $\Psi$ that does predict static strengthening. However, the data presented here suggest that in the absence of nonzero load-point shear stress (unprimed), no stress peaks 


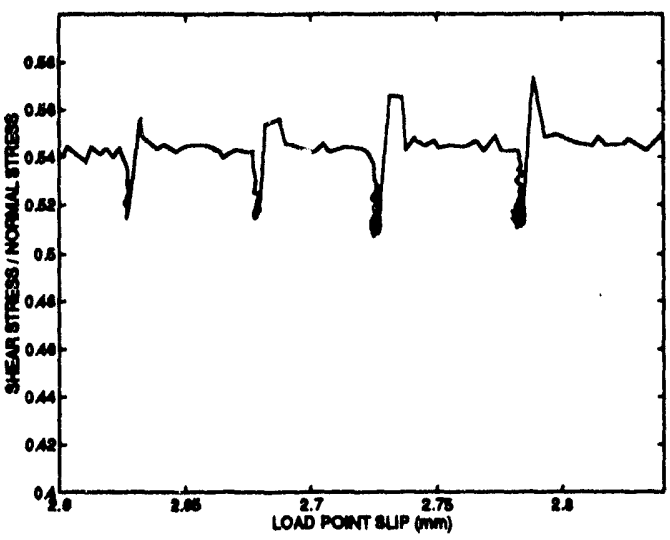

Figure 8: Variation of friction in a slide-hold-slide test. Note the stress-relaxation at each displacement hold, and the transient strengthening.

reflecting time-dependent strengthening develop. If Ruina's assertion is correct, then there must be some very small amount of slip occurring in the primed, stationary phases. Evidently, the amount of slip must be smaller than the slip resolution of the equipment used here (Fig. 8).

Both the static portions of the rate tests on an unprimed surface (Fig. 5) and on the primed surface (Fig. 6) are accompanied by an increasing shear stress. Thus, one might expect some microscopic slippage, which by Ruina's argument should lead to peaked curves resulting from strengthening. The lack of stress peak development in the unprimed surface condition, indicates that there is something more to it. The main difference is that the rate tests on the primed surface are preceded by a steady-state sliding phase that is not terminated by a momentary removal of the normal stress. Thus, it appears that when the normal stress is allowed to go to zero, the memory of that past slip history, which is reflected in $\Psi=0$, is erased.

\section{Creep}

Creep is defined just as it is for solid materials: deformation (in this instance slip) at constant stress. Creep tests were done on the surface in both initial states, unprimed and primed.

\subsection{Unprimed Surface}

A number of short-term (minutes to hours) creep tests at various stress levels were done on the unprimed surface. The load-point displacement was increased until the corresponding shear stress 


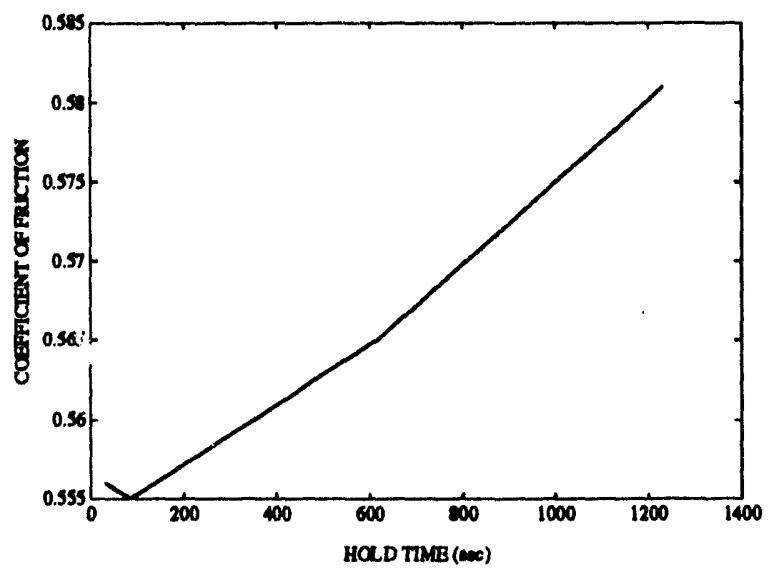

Figure 9: The effect of displacement holds of various lengths on the strength.

increased to a preselected level where the control mode was switched to load; i.e., the load point was maintained at constant load. No slip was recorded in any of these tests.

\subsection{Primed Surface}

Several creep tests conducted on a primed surface are shown in Figure 10. The small plot at the top of the figure shows the entire test record. Starting in the unprimed condition at $\sigma=5 \mathrm{MPa}$, the joint was slid at a constant velocity to about $0.14 \mathrm{~mm}$, where the displacement was put in hold and the control mode switched to load. When the displacement was stopped, the stress relaxed, nearly instantaneously, to a little less than $0.6 \sigma$. Thus, this represents a constant stress test at about $95 \%$ of the sliding stress. No slip was observed in 2.5 hours, at which time the stress was raised to $0.617 \sigma$ (about 99\% of the slip stress). After something less than an hour, no creep was observed, so the stress was raised to $0.623 \sigma$, or greater than the stress required for sliding under dynamic conditions immediately preceding the creep experiments. Again, no creep was observed. Finally, the control mode was switched back to displacement and was increased at the former rate causing the stress to jump to $0.670 \sigma$ before slip reinitiated and the stress rapidly resumed its former value. Evidently, microscopic slippage that occurs in association with the stress relaxation, leads to a strengthening, $a>0$, that actually prevents classical creep. In fact, at $\mu=.623$, one whould expect, based on experience with creep of solids, accelerating creep. 


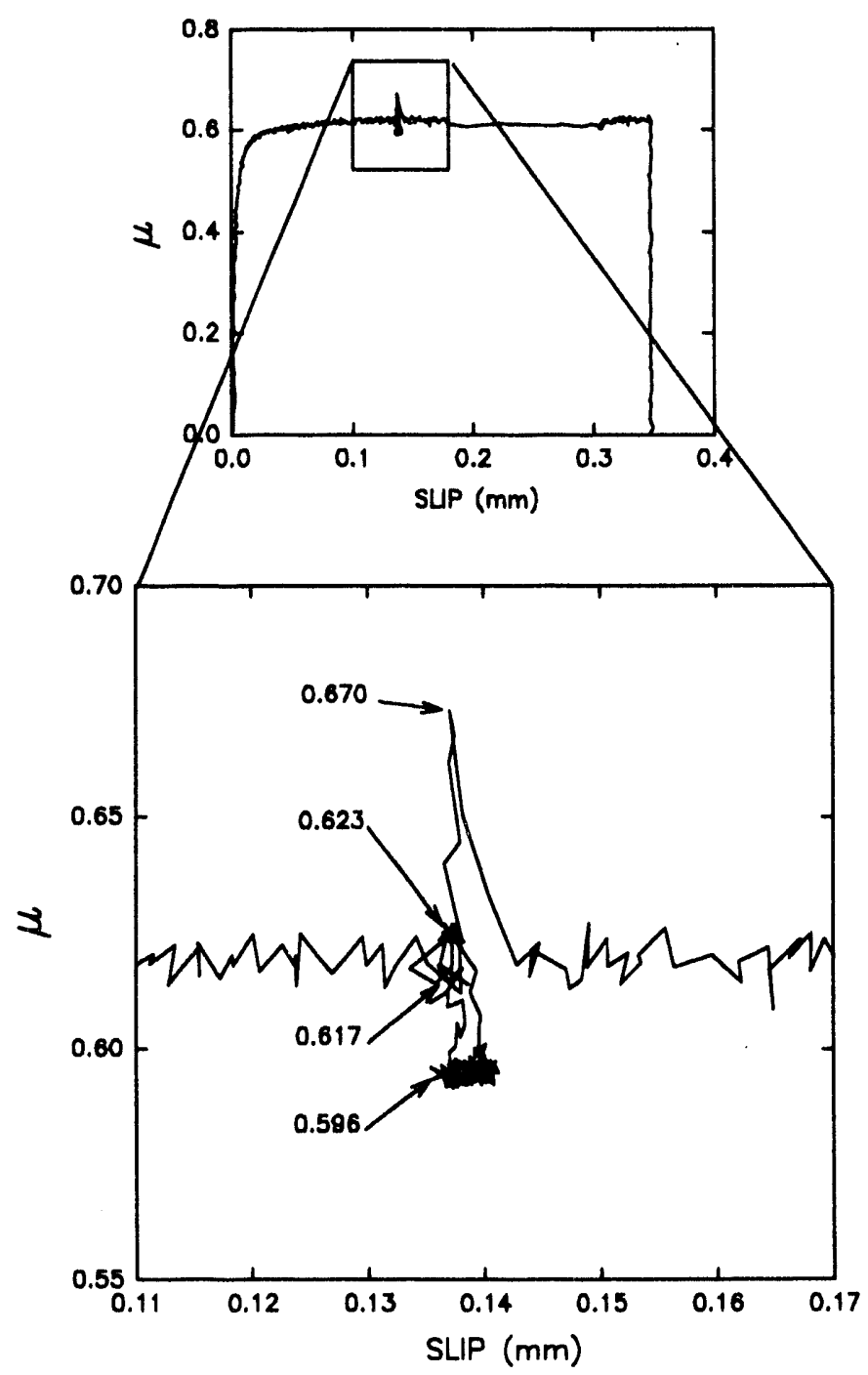

Figure 10: A creep test near the slip stress on a primed surface. 


\section{Conclusions}

Rotary shear experiments at constant normal stress have been run on a smooth, artificial joint in Topopah Spring Member tuff. In general, this rock behaves much like other silicate rocks in its sensitivity to velocity changes and displacement history, but this program has highlighted some new and relatively unexplored behavior. Two initial states, unprimed and primed exhibit qualitatively and quantitatively different responses. The result that there are two limiting initial conditions, primed and unprimed, indicates that inferring rock mass response from in situ or laboratory properties could lead to errors without substantially improved understanding of the initial conditions of real joints. It is important to differentiate between the continued deformation of a joint that has been relieved of in situ stress from one that has not been.

In the steady-state friction regime, the slip behavior of this rock is well-described by the rateand state-dependent constitutive law. Fractures in a steady-state exhibit velocity weakening at the low normal stresses used here, and $b-a \approx 0.014$. This type of constitutive reponse, in combination with the relatively low modulus of the rock mass compared with intact rock, and the well-known stress concentrations that occur in the vicinity of underground openings, suggests that dynamic instabilities may manifest themselves in the form of acoustic emissions or, possibly, higher amplitude events. These results indicate that acoustic monitoring of the repository may be useful from a safety standpoint.

Short-term creep tests in both the primed and unprimed states show no time-dependent slip. In the primed state, the shear stress to reinitiate slip after a nominal constant slip period, exceeds the immediately preceding steady-state value. Thus, some mechanism, either time-dependent strengthening of static friction, or firiction increases due to microscopic slip as suggested by the rate- and state-dependent frcition law, is preventing slip at constant stress.

The effect of submerging the joint in water shows that the friction is higher for wet joints than dry ones, but that there is little difference in the trend or magnitude of the rate effect. Presumably, this results from the fact that the largest changes due to moisture occur in the first fractions of a percent of water content, and thus experiments run in the so-called laboratory air-dry (but still in ambient humidity) condition already have the necessary water content to behave similarly to saturated samples. Thus, conclusions based on air-dry samples will still pertain to joints in situ.

\section{References}

Blanpied, M. L., T. E. Tullis, J. D. Weeks, Frictional behavior of granite at low and high sliding velocities, Geophys. Res. Let., 14, 554-557, 1987. (NNA.900918.0009) 
Blanpied, M. L., D. A. Lockner and J.D. Byerlee, Fault stability inferred from granite sliding experiments at hydrothermal condtions, Geophy. Res. Let., 18, 609-612, 1991. (NNA.930330.0073)

Brace, W. F., and J. D. Byerlee, Stick-slip as mechanism for earthquakes, Science, 153, 990-992, 1966. (NNA.930330.0074)

Christensen, R. J., S. R. Swanson, and W. S. Brown, Torsional shear measurements of the frictional properites of Westerly granite, in Advances in Rock Mechanics, Proc. 3rd Cong. Intern. Soc. Rock Mech., 221-225, 1974. (NNA.900919.0172)

Dieterich, J. H., Time-dependent friction in rocks, J. Geophys. Res, 77, 3690-3697, 1972. (HQS.880517.1159)

Dieterich, J. H., Time-dependent friction and the mechanics of stick-slip, Pageoph, 116, 790-806, 1978. (HQS.880517.1161)

Dieterich, J. H., Modeling of rock friction: 1 . Experimental results and constitutive equations, $J$. Geophys. Res., 84,2161-2168, 1979. (NNA.900918.0016)

Dieterich, J. H., Constitutive properites of faults with simulated gouge, in Mechanical Behavior of Crustal Rocks: The Handin Volume, Geophys. Monogr. Ser., 24, edited by N. L. Carter, M. Friedman, J. M. Logan, D. W. Strearns, 103-120, 1981. (NNA.900919.0173)

Dieterich, J. H., and G. Conrad, Effect of humidity on time- and velocity-dependent friction in rocks, J. Geophysical Res., 89, 4196-4202, 1981. (NNA.900918.0017)

Gu, J.-C., J. R. Rice, A. L. Ruina, and S. T. Tse, Slip motion and stability of a single degree of freedom elastic system with rate and state dependent friction, J. Mech. Phys. Solids, 32, 167-196, 1984. (NNA.900918.0018)

Holcomb, D. J., and L. W. Teufel, Acoustic emissions during deformation of intact and jointed welded tuff, Sandia National Laboratories Tech. Rep., SAND82-1003, Albuquerque, NM, 1982. (SRX.820817.0119)

Kutter, H. K., Rotary shear testing of rock joints, in Proc. 3rd Cong. of the Intern. Soc. for Rock Mech., National Academy of Sciences, Washington, D.C., 254-262, 1974. (NNA.900919.0174)

Marone, C., C. B. Raleigh, and C. H. Scholz, Frictional behavior and constitutive modeling of simulated fault gouge, J. Geophys. Res., 95, 7000-7025, 1990. (NNA.930330.0075)

Olsson, W. A., A dislocation model of the stress history dependence of frictional slip, J. Geophys. Res., 89, 9271-9280, 1984. (NNA.900403.0279)

Olsson, W. A., The effects of changes in normal stress on rock friction, in Constitutive Laws for Engineering Materials: Theory and Applications, ed. C. S. Desai, E. Krempl, P. D. Kiousis, T. Kundu, p. 1059-1066, Elsevier, New York, 1987a. (NNA.910207.0028) 
Olsson, W. A., Rock Joint Compliance Studies, Sandia National Laboratories Tech. Rep., SAND86-0177, Albuquerque, NM, 1987b. (NNA.891019.0291)

Olsson, W. A., Compliance and Strength of Artificial Joints in Topopah Spring Tuff, Sandia National Laboratories Tech. Rep., SAND88-0660, Albuquerque, NM, 1988. (NNA.881202.0205)

Olsson, W. A., The effects of normal stress history on rock friction, in Key Questions in Rock Mechanics: Proceedings of the 29th U.S. Symp. Rock Mechanics, eds. P. A. Cundall, R. L. Sterling, and A. M. Starfield, 111-117, Balkema, Brookfield, 1988. (NNA.900403.0382)

Olsson, W. A., The effects of shear and normal stress paths on rock friction, in Rock Joints: Proceedings of the International Symposium on Rock Joints, eds. N. Barton and O. Stephansson, 475-479, Balkema, Brookfield, 1990. (NNA.900426.0053)

Olsson, W. A., The effect of slip on the flow of fluid through a fracture, Geophys. Res. Let., 19, 541-543, 1992. (NNA.930330.0076)

Olsson, W. A., and S. R. Brown, Hydromechanical response of a fracture undergoing compression and shear, accepted for publication in Proc. 34 ${ }^{\text {th }}$ U. S. Symposium on Rock Mechanics, 1993. (NNA.940301.0034)

Price, R. H., J. R. Connolly, and K. Keil, Petrologic and mechanical properties of outcrop samples of the welded, devitrified Topopah Spring Member of the Paintbrush tuff, SAND86-1131, Sandia National Laboratories, Albuquerque, NM, 1987. (HQS.880517.1704)

Rice, J. R., Constitutive relations for fault slip and earthquake instabilities, PAGEOPH, 121, 443-475, 1983. (NNA.930330.0077)

Rice, J. R., and J.-C. Gu, Earthquake aftereffects and triggered seismic phenomena, PAGEOPH, $121,187-219,1983$. (NNA.930330.0078)

Rice, J. R. and A. L. Ruina, Stability of steady frictional slipping, J. Appl. Mech., 50, 343-349, 1983. (NNA.930414.0032)

Ruina, A., Friction laws and instabilities: a quasistatic analysis of some dry frictional behavior, Report No. 21 (Ph. D. Thesis), Division of Engineering, Brown University, Providence, R. I., 1980. (NNA.940301.0035)

Ruina, A., Slip instability and state variable friction laws, J. Geophys. Res., 88, 10,359-10,370, 1983. (NNA.930330.0079)

Teufel, L. W., Frictional properties of jointed welded tuff, Sandia National Laboratories Tech. Rep., SAND81-0212, Albuquerque, NM, 1982. (HQS.880517.2356)

Tullis, T. E., and J. D. Weeks, Constitutive behavior and stability of frictional siding of granite, PAGEOPH, 124, 383-414, 1986. (NNA.930330.0080) 
Weeks, J. D., and T. E. Tullis, Frictional sliding of dolomite: a variation in constitutive behavior, J. Geophys. Res., 90, 7821-7826, 1985. (NNA.930330.0081)

Wong, I. G., Recent developments in rockburst and mine seismicity research, in Rock Mechanics, Proc. 33rd U. S. Rock Mech. Symp., eds. J. R. Tillerson and W. R. Wawersik, 1103-1112, Balkema, Rotterdam, 1992. (NNA.930414.0033)

$\mathrm{Xu}, \mathrm{S}$. and M. H. de Frietas, Use of a rotary shear box for testing the shear strength of rock joints, Geotechnique, 38, 301-309, 1988. (NNA.900918.0012)

Yoshioka, N., and C. H. Scholz, Elastic properties of contacting surfaces under normal and shear loads 2. Comparison of theory with experiment, J. Geophys. Res., 94, 17691-17700, 1989. (NNA.900403.0393) 


\title{
APPENDIX \\ Information from the Reference Information Base Used in this Report
}

This report contains no information from the Reference Information Base.

\author{
Candidate Information \\ for the \\ Reference Information Base
}

This report contains no candidate information for the Reference Information Base.

\author{
Candidate Information \\ for the \\ Geographic Nodal Information Study \\ and Evaluation System
}

This report contains no candidate information for the Geographic Nodal Information Study and Evaluation System. 


\section{YUCCA MOUNTAIN SITE CHARACTERIZATION PROJECT}

\section{DISTRIBUTION LIST}

1

D.A. Dreyfus (RW-1)

Director

OCRWM

US Department of Energy

1000 Independence Avenue SW

Washington, DC 20585

1 L.H. Barrett (RW-2)

Acting Deputy Director

OCRWM

US Department of Energy

1000 Independence Avenue SW

Washington, DC 20585

1

J.D. Saltzman (RW-4)

Office of Strategic Planning and

International Programs

OCRWM

US Department of Energy

1000 Independence Avenue SW

Washington, DC 20585

1 J.D. Saltzman (RW-5)

Office of External Relations

OCRWM

US Department of Energy

1000 Independence Avenue SW

Washington, DC 20585

1 Samuel Rousso (RW-10)

Orfice of Program and Resource Mgt.

OCRWM

US Department of Energy

1000 Independence Avenue SW

Washington, DC 20585

1

J. C. Bresee (RW-10)

OCRWM

US Department of Energy

1000 Independence Avenue SW

Washington, DC 20585
1

R.M. Nelson (RW-20)

Omce of Geologic Disposal

OCRWM

US Department of Enerzy

1000 Independence Avenue, SW

Washington, DC 20585

1 S. J. Brocoum (RW-22)

Analysis and Verification Division OCRWM

US Department of Energy

1000 Independence Avenue SW

Washington, DC 2585

1

D. Shelor (RW-30)

Omce of Systems and Compliance

OCRWM

US Department of Energy

1000 Independence Avenue, SW

Washington, DC 20585

1 J. Roberts (RW-33)

Director, Regulatory Compliance

Division

OCRWM

US Department of Energy

1000 Independence Avenue, SW

Washington, DC 20585

1

G. J. Parker (RW-332)

Reg. Policy/Requirements Branch OCRWM

US Department of Energy

1000 Independence Avenue, SW

Washington, DC 20585

1

R. A. Milner (RW-40)

Ofice of Storage and

Transporation

OCRWM

US Department of Energy

1000 Independence Avenue, SW

Washington, DC 20585 
Ofince of Contract Business

Management

OCRWM

US Department of Energy

1000 Independence Avenue, SW

Washington, DC 20585

1

T. Wood (RW-52)

Director, M\&O Management Division OCRWM

US Department of Energy

1000 Independence Avenue, SW

Washington, DC 20585

4 Victoria F. Reich, Librarian

Nuclear Waste Technical Review Board

1100 Wilson Blvd, Suite 910

Arlington, VA 22209

5 R.M. Nelson Jr, Acting Project Manager

Yucca Mountain Site

Characterization Project Omice

US Department of Energy

P.O. Box 98608--MS 523

Las Vegas, NV 89193-8608

1

C. L. West, Director

Office of External Affairs

DOE Nevada Field Office

US Department of Energy

P.O. Box 98518

Las Vegas, NV 89193-8518

8 Technical Information Oncer

DOE Nevada Field Omice

US Department of Energy

P.O. Box 98518

Las Vegas, NV 89193-8518

1 P. K. Fitzsimmons, Technical Advisor

Office of Assistant Manager for

Environmental Safety and

Health

DOE Nevada Field Ofrice

US Department of Energy

P.O. Box 98518

Las Vegas, NV 89193-8518
D. R. Elle, Director

Environmental Protection and Division

DOE Nevada Field Omce

US Department of Energy

P.O. Box 98518

Las Vegas, NV 89193-8518

1

Repository Licensing \& Quality

Assurance

Project Directorate

Division of Waste Management

US NRC

Washington, DC 20555

1

Senior Project Manager for Yucca Mountain

Repository Project Branch

Division of Waste Management

US NRC

Washington, DC 20555

$1 \quad$ NRC Document Control Desk

Division of Waste Management

US NRC

Washington, DC 20555

$1 \quad$ Philip S. Justus

NRC Site Representive

301 E Stewart Avenue, Room 203

Las Vegas, NV 89101

1 E. P. Binnall

Field Systems Group Leader

Building 50B/4235

Lawrence Berkeley Laboratory

Berkeley, CA 94\%/20

1 Center for Nuclear Waste

Regulatory Analyses

6220 Culebra Road

Drawer 28510

San Antonio, TX 78284

3

W. L. Clarke

Technical Project Omcer - YMP

Attn: YMP/LRC

Lawrence Livermore National

Laboratory

P.0. Box 5514

Livermore, CA 94551 
J. A. Blink

Deputy Project Leader

Lawrence Livermore National

Laboratory

101 Convention Center Drive

Suite 820, MS 527

Las Vegas, NV 89109

4

J. A. Canepa

Technical Project Omcer - YMP

N-5, Mail Stop J521

Los Alamos National Laboratory

P.O. Box 1663

Los Alamos, NM 87545

1

H. N. Kalia

Exploratory Shaft Test Manager

Los Alamos National Laboratory

Mail Stop 527

101 Convention Center Dr., \#820

Las Vegas, NV 89101

1

N. Z. Elkins

Deputy Technical Project Omicer

Los Alamos National Laboratory Mail Stop 527

101 Convention Center Dr., \#820

Las Vegas, NV 89101

L. E. Shephard

Technical Project Officer - YMP

Sandia National Laboratories

Organization 6302

P.O. Box 5800

Albuquerque, NM 87185

1

J. F. Devine

Asst Director of Engineering Geology

US Geological Survey

106 National Center

12201 Sunrise Valley Drive

Reston, VA 22092

1 L. R. Hayes

Technical Project Omicer

Yucca Mountain Project Branch

MS 425

US Geological Survey

P.O. Box 25046

Denver, CO 80225
V. R. Schneider

Asst. Chief Hydrologist--MS 414

Omce of Program Coordination

and Technical Support

US Geological Survey

12201 Sunrise Valley Drive

Reston, VA 22092

1

J. S. Stuckless

Geologic Division Coordinator

MS 913

Yucca Mountain Project

US Geological Survey

P.O. Box 25046

Denver, CO 80225

1

D. H. Appel, Chief

Hydrologic Investigations Program

MS 421

US Geological Survey

P.O. Box 25046

Denver, CO 80225

1

E. J. Helley

Branch of Western Regional Geology

MS 427

US Geological Survey

345 Middlefield Road

Menlo Park, CA 94025

1 R. W. Craig, Chief

Nevada Operations Office

US Geological Survey

101 Convention Center Drive

Suite 860, MS 509

Las Vegas, NV 89109

1 D. Zesiger

US Geological Survey

101 Conventional Center Drive

Suite 860, MS 509

Las Vegas, NV 89109

1

G. L. Ducret, Associate Chief

Yucca Mountain Project Division

US Geological Survey

P.O. Box 25046

421 Federal Center

Denver, CO 80225 
A. L. Flint

US Geological Survey

MS 721

P.O. Box 327

Mercury, NV 89023

1

D. A. Beck

Water Resources Division, USGS

6770 S Paradise Road

Las Vegas, NV 89119

$1 \quad$ P. A. Glancy

US Geological Survey

Federal Building, Room 224

Carson City, NV 89701

1 Sherman S.C. Wu

US Geological Survey

2255 N. Gemini Drive

Flagstaff, AZ 86001

1 J. H. Sass - USGS

Branch of Tectonophysics

2255 N Gemini Drive

Flagstaff, AZ 86001

1 DeWayne Campbell

Technical Project Officer - YMP

US Bureau of Reclamation

Code D-3790

P.O. Box 25007

Denver, CO 80225

1 J. M. LaMonaca

Records Specialist

US Geological Survey

421 Feder: Center

P.O. Box 25046

Denver, CO 80225

1

W. R. Keefer - USGS

913 Federal Center

P.O. Box 25)46

Denver, CO 80225

1 M. D. Voegele

Technical Project Officer - YMP

SAIC

101 Convention Center Drive

Suite 407

Las Vegas, NV 89109
2

L. D. Foust

Nevada Site Manager

TRW Environmental Safety

Systems

101 Convention Center Drive

Suite 540, MS 423

Las Vegas, NV 89109

1 C. E. Ezra

YMP Support Omce Manager

EG\&G Energy Measurements Inc MS V -02

P.O. Box 1912

Las Vegas, NV 89125

1 E. L. Snow, Program Manager

Roy F. Weston Inc

955 L'Enfant Plaza SW

Washington, DC 20024

1

Technical Information Center

Roy F. Weston Inc

955 L'Enfant Plaza SW

Washington, DC 20024

1

D. Hedges, Vice President, QA

Roy F. Weston Inc

4425 Spring Mountain Road

Suite $\mathbf{3 0 0}$

Las Vegas, NV 89102

1 D. L. Fraser, General Manager

Reynolds Electrical \&

Engineering Co, Inc

MS 555

P.O. Box 98521

Las Vegas, NV 89193-8521

1 B. W. Colston, President and General Manager

Las Vegas Branch

Raytheon Services Nevada

MS 416

P.O. Box 95487

Las Vegas, NV 89193-5487

$1 \quad$ R. L. Bullock

Technical Project Omcer - YMP

Raytheon Services Nevada

Suite P-250, MS 403

101 Convention Center Drive

Las Vegas, NV 89109 
PASS Program

Pacific Northwest Laboratories

P.O. Box 999

Richland, WA 99352

A. T. Tamura

Science and Technology Division

OSTI

US Department of Energy

P.O. Box 62

Oak Ridge, TN 37831

1 Carlos G. Bell Jr

Professor of Civil Engineering

Civil and Mechanical Engineering Dept.

University of Nevada, Las Vegas

4505 S Maryland Parkway

Las Vegas, NV 89154

1 P. J. Weeden, Acting Director

Nuclear Radiation Assessment Div.

US EPA

Environmental Monitoring

Systems Lab

P.O. Box 93478

Las Vegas, NV 89193-3478

$1 \quad$ ONWI Library

Battelle Columbus Laboratory

Office of Nuclear Waste Isolation

505 King Avenue

Columbus, OH 43201

1 T. Hay, Executive Assistant

Office of the Governor

State of Nevada

Capitol Complex

Carson City, NV 89710

3 R. R. Loux

Executive Director

Agency for Nuclear Projects

State of Nevada

Evergreen Center, Suite 252

1802 N. Carson Street

Carson City, NV 89710
C.H. Johnson

Technical Program Manager Agency for Nuclear Projects State of Nevada

Evergreen Center, Suite 252 1802 N. Carson Street

Carson City, NV 89710

1 John Fordham

Water Resources Center

Desert Research Institute

P.O. Box 60220

Reno, NV 89506

1

David Rhode

Desert Research Institute

P.O. Box 60220

Reno, NV 89506

1

Eric Anderson

Mountain West Research-

Southwest Inc

2901 N Central Avenue \#1000

Phoenix, AZ 85012-2730

1

The Honorable Cyril Schank

Chairman

Churchill County Board of

Commissioners

$190 \mathrm{~W}$ First Street

Fallon, NV 89406

1 Dennis Bechtel, Coordinator

Nuclear Waste Division

Clark County Department of

Comprehensive Planning

301 E Clark Avenue, Suite $\mathbf{5 7 0}$

Las Vegas, NV 89101

1 Juanita D. Hofiman

Nuclear Waste Repository

Oversight Program

Esmeralda County

P.O. Box 490

Goldfield, NV 89013

1 Eureka County Board of Commissloners

Yucca Mountain Information

Once

P.O. Box 714

Eureka, NV 89316 
Brad Mettam

inyo County Yucca Mountain

Repository Assessment Once

Drawer L

Independence, CA 93526

1 Lander County Board of

Commissioners

315 South Humbolt

Battle Mountain, NV 89820

1 Vernon E. Poe

Omice of Nuclear Projects

Mineral County

P.O. Box 1026

Hawthorne, NV 89415

1 Les W. Bradshaw

Program Manager

Nye County Nuclear Waste

Repository Program

P.O. Box 153

Tonopah, NV 89049

$1 \quad$ Florindo Mariani

White Pine County Nuclear

Waste Project Ofice

457 Fifth Street

Ely, NV 89301

1 Judy Foremaster

City of Caliente Nuclear Waste

Project Office

P.O. Box 158

Caliente, NV 89008

$1 \quad$ Phillip A. Niedzielski-Eichner

Nye County Nuclear Waste

Repository Project Omce

P.O. Box 221274

Chantilly, VA 22022-1274

1 Jason Pitts

Lincoln County Nuclear Waste

Project Office

Lincoln County Courthouse

Pioche, NV 89043
Economic Development Dept.

City of Las Vegas

400 E. Stewart Avenue

Las Vegas, NV 89101

1 Commmunity Planning and

Development

City of North Las Vegas

P.O. Box 4086

North Las Vegas, NV 89030

1

Community Development and

Planning

City of Boulder City

P.O. Box 61350

Boulder City, NV 89006

1 Commission of the European

Communities

200 Rue de la Loi

B-1049 Brussells

BELGIUM

M. J. Dorsey, Librarian

YMP Research and Study Center

Reynolds Electrical \&

Engineering Co Inc

MS 407

P.O. Box 98521

Las Vegas, NV 89193-8521

1 Amy Anderson

Argonne National Laboratory

Building 362

$9700 \mathrm{~S}$ Cass Avenue

Argonne, IL 60439

1 Steve Bradhurst

P.O. Box 1510

Reno, NV 89505

1

Michael L. Baughman

35 Clark Road

Fiskdale, MA 01518

$1 \quad$ Glenn Van Roekel

Director of Community

Development

City of Caliente

P.O. Box 158

Callente, NV 89008 
1 Ray Williams, Jr

P.O. Box 10

Austin, NV 89310

$1 \quad$ Nye County District Attorney

P.O. Box 593

Tonopah, NV 89049

$1 \quad$ William Offutt

Nye County Manager

Tonopah, NV 89049

1 Charles Thistlethwaite, AICP

Associate Planner

Inyo County Planning Department

Drawer L

Independence, CA 93526

1

R. F. Pritchett

Technical Project Omicer - YMP

Reynolds Electrical \&

Engineering Company Inc MS 408

P.O. Box 98521

Las Vegas, NV 89193-8521

1

Dr. Moses Karakouzian

1751 E Reno \#125

Las Vegas, NV 89119

1

Michael L. Blanpied

USGS

MS 977

345 Middlefield Road

Menlo Park, CA 94024

1 James H. Dieterich

USGS

MS 977

345 Middlefield Road

Menlo Park, CA 94024

1 C. Scholtz

Lamont-Doherty Geo.

Observatory

Palisades, NY 10964

$1 \quad$ Professsor Terry Tullis

Dept of Geological Sciences

Brown University

Providence, RI 02912
1

\author{
Dr. John Weeks \\ Dept of Geological Sciences \\ Brown University \\ Providence, RI 02912
}

MS

$1 \quad 1325$

21330

21330

L.S. Costin, 6313

G.M. Gerstner-Miller, 6352

100/1232714/SAND92-2333/QA

G.M. Gerstner-Miller, 6352

DRMS Files (Data Set 51/L02-

06/04/84)

$20 \quad 1330 \quad$ WMT Library, 6352

$1 \quad 1324$

10827

$1 \quad 1375$

50899

10619

$10 \quad 1119$

P.B. Davies, 6115

P.J. Hommert, 1502

D.A. Dahlgren, 4400

Technical Library, 7141

Technical Publications, 7151

Document Processing for

DOE/OSTI, 7613-2

19018

Central Technical Files, 8523-2

$1 \quad 0751$

10751

$1 \quad 0751$

$20 \quad 0751$

$10 \quad 1325$
W.R. Wawersik, 6117

S.R. Brown, 6117

J.T. Fredrick, 6117

W.A. Olsson, 6117

R.H. Price, 6313 
SAND92-2333

The number in the lower right-hand corner is an accession number used for Office of Civilian Radioactive Waste Management purposes only. It should not be used when ordering this publication. 


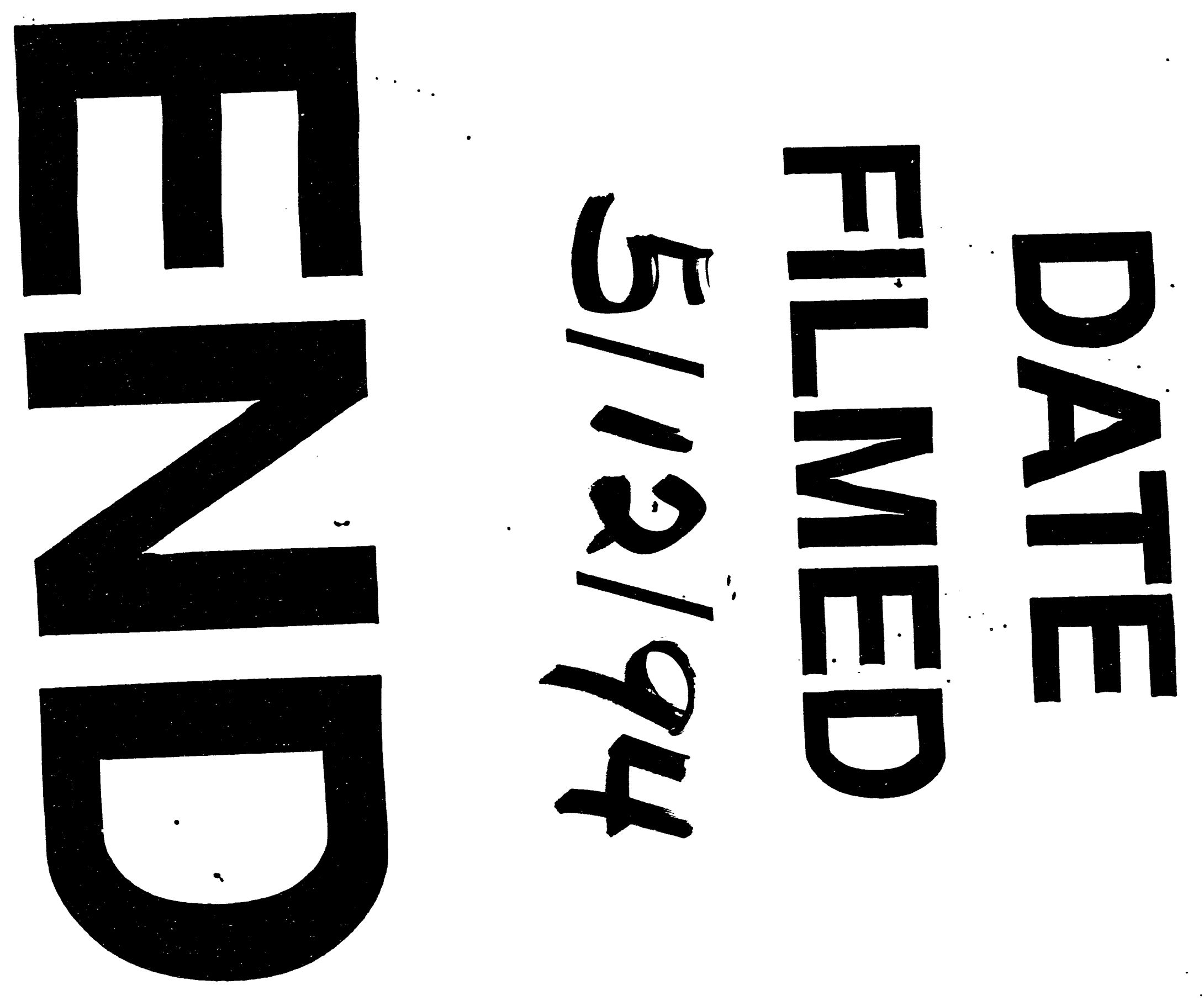




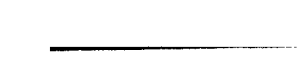

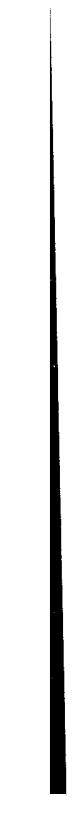

